\title{
EXPLORAÇÃO DE AMBIENTES DESCONHECIDOS ESTRUTURADOS COM SISTEMAS MULTI-ROBÔS COORDENADOS
}

\author{
Victor Boeing Ribeiro*, Jean-Marie Alexandre Farines*, José Eduardo Ribeiro Cury* \\ * Universidade Federal de Santa Catarina \\ Florianópolis, SC, Brasil
}

Emails: boeing@das.ufsc.br, farines@das.ufsc.br, cury@das.ufsc.br

\begin{abstract}
This paper presents a method of exploring unknown structured environments with multiple robots. While exploring the environment, the robots interpret sensorial information inserting them into a single global topological map. Metric data is also collected and incorporated into the map, making easier the resolution of problems as the loop closing. The proposed method uses the concept of boundaries to define the tasks of the system and evaluates the use of heuristics to allocate tasks to the robots. A decoupled approach is used for path planning, in which paths are calculated for each robot and then conflicts between them are resolved. Experimental results validate the functionality and efficiency of the proposed method.
\end{abstract}

Keywords_ multi-robot systems, mapping, path planning, task allocation

Resumo - Este trabalho apresenta um método de exploração de ambientes desconhecidos estruturados com múltiplos robôs. Enquanto exploram o ambiente, os robôs interpretam informações sensoriais inserindo-as em um mapa topológico global único. Dados métricos são também coletados e incorporados ao mapa, facilitando a resolução de problemas como o de fechamento de loops. O método proposto utiliza o conceito de fronteiras para definir as tarefas do sistema e avalia a utilização de heurísticas na alocação das tarefas aos robôs. Uma abordagem desacoplada é utilizada para o planejamento de trajetória, na qual caminhos são calculados para cada robô e conflitos entre os mesmos são tratados posteriormente. Resultados experimentais validam a funcionalidade e eficiência do método proposto.

Palavras-chave — sistemas multi-robôs, mapeamento, planejamento de trajetória, alocação de tarefas

\section{Introdução}

A atividade de busca e exploração em ambientes desconhecidos é um dos problemas fundamentais em sistemas robóticos autônomos. São diversas as aplicações desse tipo de sistema, desde a substituição de operadores humanos em atividades cuja execução apresenta risco elevado até a automação de atividades cotidianas.

O uso de múltiplos robôs geralmente apresenta diversas vantagens sobre sistemas com um único robô (Burgard et al., 2005). Sistemas multirobôs têm o potencial de realizar tarefas mais rapidamente, possuem maior tolerância a faltas e apresentam redundância de informações, o que contribui com a redução de incertezas. Quando a exploração de ambientes desconhecidos é realizada simultaneamente por múltiplos robôs, essas características são levadas em conta para o comportamento do sistema. No entanto, desafios inerentes à sistemas multi-robôs passam também a compor o problema de exploração como a necessidade de coordenar a movimentação dos múltiplos robôs para evitar colisões e bloqueios.

Muitos trabalhos tem sido desenvolvidos no contexto de exploração e mapeamento de ambientes desconhecidos, porém, devido aos diversos desafios inerentes a esse tema, esses trabalhos geralmente se focam em um dos problemas ou até mesmo em aplicações específicas.

Em Marjovi and Marques (2011) são aplicadas técnicas de exploração de ambientes desconhecidos com múltiplos robôs para identificação de fon- tes de vazamento de gás em ambientes industriais. Sua principal contribuição é a utilização da medição de concentração de odores para decidir os caminhos a serem tomados pelos robôs. Já Burgard et al. (2005) trabalha na determinação dos pontos de maior utilidade do ambiente durante a atribuição de atividades para os múltiplos robôs. A ideia principal consiste em evitar que vários robôs se movam para uma mesma região, fazendo com que a utilidade de um ponto seja inversamente proporcional a quantidade de robôs presente nos seus arredores. Em Stachniss et al. (2006) a atribuição de um alvo a ser explorado considera também o tipo de lugar em que este está inserido antes de designar um robô para explorá-lo, como corredores ou salas. A prioridade é visitar lugares que potencialmente forneçam mais lugares alvo a serem explorados, possibilitando enviar os robôs para regiões distantes umas das outras.

Técnicas têm sido desenvolvidas para calcular trajetórias eficientes para que múltiplos robôs alcancem pontos específicos em um ambiente conhecido. Em Pavei (2011) são apresentadas técnicas de planejamento de trajetória baseadas na teoria de controle supervisório e também utilizando autômato-jogo temporizado. Já em Carvalho (2012), o problema de planejamento de trajetória é tratado através de métodos baseados em estruturas de jogos. Ambos os trabalhos geram coordenadores capazes de lidar com especificações que garantam segurança do sistema.

O objetivo principal desse trabalho consiste 
em propor um método de exploração de ambientes desconhecidos estruturados com múltiplos robôs. O método proposto irá tratar de aspectos como o processo de interpretação das informações sensoriais adquiridas pelos robôs e da integração delas em uma representação coerente do ambiente. Irá tratar também do problema de planejamento de trajetória, que refere-se ao processo de cálculo de uma série ações a serem executadas pelos robôs para realizar a exploração do ambiente de forma eficiente e segura.

\section{A exploração de ambientes desconhecidos}

Em Thrun et al. (2002) são apontados os principais aspectos considerados desafios na tarefa de exploração e construção do mapa de um ambiente desconhecido. O primeiro deles é a aquisição de informações dos arredores do robô. Os sensores utilizados para realizar essa aquisição apresentam limitações em relação ao alcance: apenas uma pequena porção ao redor do robô é de fato medida, fazendo-se necessário que o robô explore o restante do ambiente para obter uma informação global. Além disso, sensores estão sujeitos a ruídos e erros de medição de distribuição frequentemente desconhecida, os quais podem levar a conclusões errôneas a respeito do ambiente.

Um segundo desafio refere-se a alta complexidade do ambiente sendo mapeado. A grande quantidade de formas que podem estar presentes em um ambiente é um fator que torna a atividade de exploração ainda mais complexa. Em geral, para lidar com esse problema, apenas algumas formas principais são extraídas do ambiente e descritas no mapa, tais como corredores, salas ou esquinas.

Outro desafio a ser considerado refere-se ao problema de determinação de equivalência de um ponto quando este é mensurado em períodos de tempo diferentes. Como a medição da localização é inexata, existe uma grande dificuldade na determinação de quando o robô retornou a um ponto já visitado, porém, através de um caminho diferente. Erros incrementais na localização do robô podem gerar incertezas de magnitude muito elevada com o passar do tempo, fazendo com que o problema de determinação de equivalência entre dois pontos tenha alta complexidade.

Um outro desafio está ligado a dinamicidade do ambiente. Mudanças nos arredores do robô durante a execução de uma exploração geram inconsistências nas leituras dos sensores, fazendo com que essas possam ser mal interpretadas, podendo levar o sistema a crer que está em um lugar diferente do que realmente está.

Um último desafio refere-se a determinação de uma estratégia de movimentação para a escolha de qual caminho seguir durante a exploração.
Quando um modelo do ambiente é conhecido, técnicas completas e ótimas podem ser aplicadas para planejar o deslocamento do robô de um ponto a outro da forma mais eficiente, porém, sem conhecimento do ambiente ou com um conhecimento parcial, a utilização dessas técnicas é limitada. Técnicas de planejamento de exploração, em geral, tomam decisões através de avaliações de fatores como os ganhos para a construção do mapa de determinado ponto, ou a energia que será gasta para se deslocar até o mesmo.

A utilização de sistemas multi-robôs para exploração de ambientes desconhecidos apresenta vantagens como o aumento da velocidade de exploração através do paralelismo, a redundância de informações que ajuda a lidar com incertezas e a maior tolerância a faltas. Apesar de serem potencialmente muito eficientes, os sistemas multi-robôs possuem uma série de questões a serem consideradas para um real aproveitamento de suas funções. Entre essas questões se destacam a arquitetura do sistema, a comunicação, a alocação de tarefas e a coordenação dos múltiplos robôs. São foco desse trabalho a alocação de tarefas e a coordenação. Com essa finalidade são assumidas uma arquitetura centralizada e comunicação sem restrições.

Em geral, aplicações envolvendo sistemas multi-robôs são caracterizadas por um conjunto de tarefas que juntas compõem o objetivo global da aplicação. Uma vez definidas essas tarefas, o desafio concentra-se em determinar qual robô deve executar cada uma delas; este desafio é chamado de alocação de tarefas. Na exploração de ambientes desconhecidos uma tarefa refere-se a alcançar determinado ponto do mapa com intuito de obter novas informações do ambiente, e a forma como essas tarefas são distribuídas entre os robôs tem um impacto direto no tempo para realização dessa exploração. Depois de atribuídas as tarefas aos robôs existe a necessidade de coordenar a execução das mesmas, controlando suas ações para prevenir colisões e bloqueios.

Para exemplificar as técnicas abordadas nesse trabalho é assumido um ambiente com características específicas. A área a ser explorada pelos robôs se trata de um ambiente indoor e estruturado, como armazéns e escritórios. Como comumente encontrado nesse tipo de ambiente, nenhum sistema de posicionamento global está disponível. A única informação existente sobre o ambiente é que se trata de uma construção estruturada, contendo corredores, esquinas, junções e cruzamentos. É assumido que o ambiente é formado somente por paredes paralelas e ortogonais. Na Figura 1 são mostrados exemplos de ambientes com as características citadas.

A consideração de que o ambiente é formado somente por paredes paralelas e perpendiculares é, porém, uma consideração bastante realista quando se trata de um ambiente indoor estrutu- 


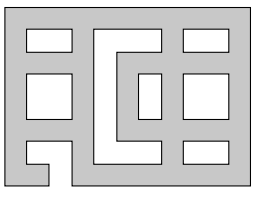

(a)

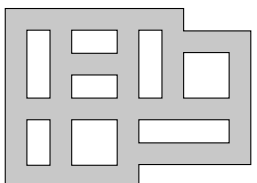

(b)
Figura 1: Exemplos de ambientes estruturados

rado. Em Bando and Yuta (2010) essas características são não só assumidas como frequentemente encontradas, como também são utilizadas para correção de erros na estimação da direção dos robôs.

É assumido que os robôs possuem, no início da exploração, uma referência global, fazendo com que seus sistemas de coordenadas sejam os mesmos e que as informações coletadas do ambiente sejam diretamente incorporadas a um único mapa global. Alguns trabalhos tratam do problema de exploração sem assumir uma referência global em comum para os robôs (Marjovi and Marques, 2011). Nesses casos, são construídos mapas locais para cada um deles e utilizadas técnicas para fusão dos mesmos. Essa fusão pode ocorrer por similaridade dos mapas locais, busca de um referencial conhecido no ambiente ou até mesmo o encontro intencional dos robôs para alinhamento dos seus sistemas de coordenadas. O problema de fusão de mapas locais, não tratado neste trabalho, é complementar ao de planejamento de trajetória.

A partir das considerações feitas do ambiente e referencial, considera-se um grupo de $\mathrm{N}$ robôs móveis, equipados com sonares e encoders, movendo-se em um plano. É assumido que todos os robôs iniciam a exploração com uma referência global em comum.

\section{Método proposto}

A atividade de exploração de ambientes desconhecidos é composta por duas etapas principais. $\mathrm{O}$ mapeamento é responsável por interpretar as informações sensoriais e, a partir delas, obter uma representação coerente do ambiente. Já o planejamento de trajetória é responsável por calcular caminhos para os robôs atingirem pontos de interesse no mapa.

Neste trabalho é utilizada uma abordagem topológica para integração das informações sensoriais e construção de um mapa que represente o ambiente de forma coerente. Nesse mapa topológico são incorporadas características métricas, facilmente mensuradas durante a exploração. O resultado é a representação do ambiente através de um grafo, representação compacta e de rápido processamento, porém, com dados da localização dos nós inseridos num sistema de coordenadas, facilitando a resolução de problemas como a determinação de equivalência entre regiões.
Como apresentado, o ambiente em questão é indoor e estruturado, formado por paredes paralelas e perpendiculares. Para a construção do mapa, é necessário determinar quais estruturas de interesse do ambiente serão identificadas e transformadas em nós do grafo. O método proposto neste trabalho utiliza o conceito de features para tal. Features são estruturas do ambiente que apresentam características padrões, tais como corredores ou esquinas. No tipo de ambiente considerado neste trabalho, cinco tipos de features podem ser extraídas: corredores, esquinas, junções, cruzamentos e becos-sem-saída (dead ends).

Com as características do ambiente assumido, pode-se considerar que o robô possui quatro possíveis orientações discretas. Com a informação da orientação do robô é possível determinar a orientação global dos corredores (horizontal ou vertical). Os corredores têm seu comprimento medido pelos robôs, neste trabalho, utilizando odometria. Essa apresenta erros incrementais, e sua utilização em longos períodos de tempo faz com que as incertezas sejam muito elevadas impossibilitando uma utilização confiável. A realização da medição somente de corredores, entretanto, não permite que essa incerteza seja muito elevada, pois os intervalos de medição são curtos e ao fim de cada corredor a odometria é reiniciada.

O mapa do ambiente é representado, então, por um grafo não-orientado onde os corredores são os arcos e as demais features são os nós. Com o comprimento e orientação dos corredores é possível calcular as coordenadas de cada nó, inserindo o grafo num sistema de coordenadas.

Para a definição do significado de tarefa neste trabalho é importante abordar o conceito de fronteira. Fronteiras são os limites entre regiões exploradas e ainda não exploradas do ambiente (Yamauchi, 1997), ou seja, as saídas de uma feature as quais não foram atravessadas por um robô. A Figura 2 identifica a presença de fronteiras em um ambiente parcialmente explorado.

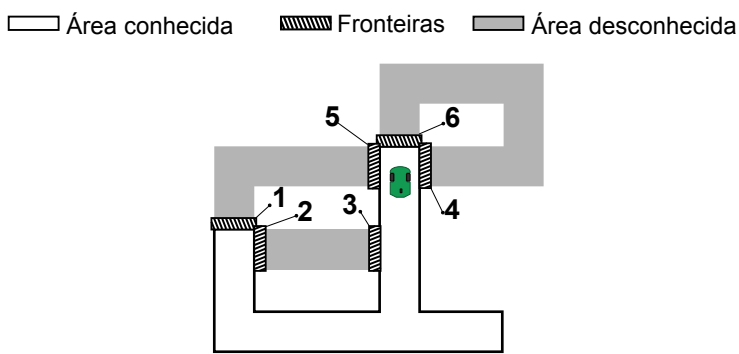

Figura 2: Identificação de fronteiras

As tarefas são definidas como o ato de deslocar-se até uma fronteira e explorá-la, afim de obter informações do ambiente para compor o mapa. A execução de todas as tarefas faz com que o objetivo global do sistema seja 
cumprido, que é a exploração total do ambiente desconhecido.

As duas próximas etapas a serem trabalhadas são a forma como essas tarefas serão distribuídas entre os robôs (alocação de tarefas) e qual o caminho a ser percorrido por cada robô para executar uma tarefa (cálculo de trajetória).

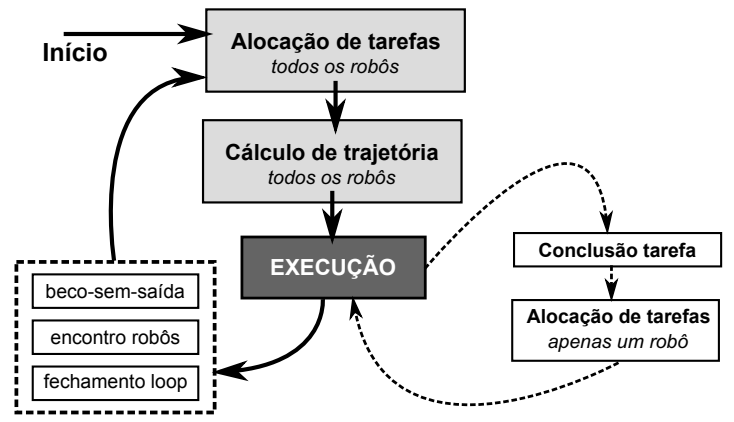

Figura 3: Esquema de execução de tarefas

A Figura 3 exemplifica o processo de execução das tarefas. Inicialmente é alocada uma tarefa para cada robô. Trajetórias são calculadas buscando evitar colisões e bloqueios para, então, os robôs iniciarem a sua execução. É bastante comum que os robôs executem as tarefas em tempos diferentes. Para evitar que os robôs fiquem ociosos aguardando os demais, sempre que possível é feita uma nova alocação de tarefa a medida que os robôs finalizam a tarefa anterior. Isso ocorre quando a alocação em questão é simples, não existindo a possibilidade de interferência com trajetórias de outros robôs e, consequentemente, a necessidade de um novo cálculo de trajetória. Um exemplo dessa situação é quando o robô, ao executar uma tarefa, descobre uma feature do tipo junção, devendo escolher entre uma fronteira à esquerda ou uma à direita.

Quando a execução de uma tarefa termina no descobrimento de um beco-sem-saída, no encontro entre robôs ou no fechamento de um loop, não é possível realizar a alocação de tarefas apenas para um robô, pois será exigido um cálculo de trajetória e uma avaliação da tarefa mais vantajosa. É feita, então, uma alocação de tarefas para todos os robôs, como mostrado na Figura 3.

\subsection{Alocação de tarefas}

A alocação de tarefas é realizada baseando-se em custos atribuídos a cada uma das fronteiras. Esses valores são determinados por heurísticas e a tarefa do alocador consiste em encontrar a distribuição de tarefas entre os robôs que apresente o menor custo.

A primeira heurística proposta refere-se a distância do robô a fronteira. A ideia mais intuitiva de distribuição de tarefas é a de alocar a cada robô a tarefa mais próxima a ele. Apesar de bastante simples, na prática essa alocação faz com que as fronteiras mais próximas sejam exploradas primeiro, evitando que os robôs tenham que atravessar caminhos já explorados para retornar a essas fronteiras no futuro. Essa alocação também evita que a distribuição de um grupo de tarefas a um grupo de robôs seja feita de forma que os robôs tenham que percorrer um caminho médio mais longo que o necessário. Nessa heurística os custos atribuídos às fronteiras são proporcionais à distância entre cada robô e a fronteira em questão.

A segunda heurística proposta refere-se à distribuição dos robôs pelo ambiente. A proximidade entre os robôs aumenta o número de interferência entre eles, provocando a inclusão de desvios e de paradas de espera em suas trajetórias. Além disso, a realização da exploração de uma mesma região do ambiente por múltiplos robôs propicia um aumento da passagem por caminhos já explorados. Todos esses fatores prejudicam a eficiência do sistema de exploração provocando um aumento no tempo total necessário para realização da atividade.

Uma vez realizada a alocação de um robô, a fronteira selecionada propaga um custo adicional às demais fronteiras. O valor desse custo é inversamente proporcional a distância da fronteira alocada em relação as demais. A distância utilizada para o cálculo dos custos, neste caso, é a distância Euclidiana, pois como o ambiente é desconhecido não se tem a informação da distância real entre as fronteiras.

Ainda com a intenção de evitar a passagem dos robôs por regiões já exploradas do ambiente, reduzindo o trabalho redundante, é proposta a heurística de fechamento de loop. Essa heurística busca dar prioridade à alocação de fronteiras cuja exploração da feature associada seja, potencialmente, finalizada em outra fronteira conhecida. A heurística é aplicada através de uma diminuição do custo das fronteiras que estejam alinhadas a outras, dentro de um certo limite de distância.

\subsection{Cálculo de trajetória}

O método proposto utiliza uma abordagem desacoplada, no qual o sistema primeiramente calcula um caminho para cada robô omitindo a existência dos demais e, numa etapa seguinte, aplica heurísticas para resolver possíveis conflitos entre os caminhos de diferentes robôs.

No método desenvolvido, uma sequência aleatória de prioridades é gerada definindo a ordem em que os caminhos dos robôs serão calculados. $\mathrm{O}$ algoritmo $\mathrm{A}^{*}$ de busca em grafos é, então, utilizado para calcular o caminho ótimo de cada robô para se deslocar da sua posição inicial até seu objetivo. Durante o cálculo das trajetórias dos robôs, eventuais conflitos são identificados e resolvidos através da comparação da trajetória gerada com as trajetórias dos robôs com maior prioridade. 
O conjunto de trajetórias gerado a partir de uma ordem de prioridades tem sua eficiência avaliada através de uma estimativa do tempo médio necessário para sua execução. Após essa avaliação, uma nova ordem de prioridades é proposta e o respectivo conjunto de trajetórias é calculado. Os conjuntos de trajetórias são comparados e aquele que apresentar resultado mais eficiente é mantido. O processo é repetido por um número arbitrário de vezes e, ao fim, o conjunto de trajetórias com a menor estimativa de tempo médio é aplicado aos robôs.

Calculada as trajetórias dos robôs, uma lista de prioridades de acesso é associada a cada nó do grafo, indicando qual a ordem em que os robôs devem acessar cada região do mapa. Sempre antes de acessar o próximo local previsto no planejamento, deve ser verificado se a prioridade de acesso pertence ao robô em questão. Caso não corresponda, o robô deve aguardar até que o robô de maior prioridade acesse e deixe o respectivo local.

Nem sempre, porém, o caminho ótimo calculado para se deslocar entre dois pontos do mapa é a melhor escolha. Isso ocorre porque o tempo que um robô deve esperar para ocupar determinada célula é, muitas vezes, superior ao tempo de percorrer uma trajetória com desvios. Para esses casos, um caminho alternativo é calculado. Esse caminho é calculado bloqueando as células que provocam a espera do robô. Se o novo caminho apresentar um resultado mais eficiente ele é mantido, caso contrário o caminho anterior é utilizado. Se o novo caminho for mais eficiente, mas ainda incluir esperas, essas esperas são também testadas. Quando o bloqueio de uma célula implicar na não existência de um caminho até a posição final desejada, o caminho anterior é mantido.

Existe uma situação que deve ser tratada com atenção especial por poder levar o sistema a uma situação de bloqueio: quando a posição inicial de um robô de menor prioridade está no caminho calculado para um robô de maior prioridade. Para resolver esse conflito, o robô de menor prioridade deve sair da trajetória do robô de maior prioridade, aguardar sua passagem, e então seguir a sua trajetória. Para que isso ocorra a trajetória de menor prioridade é dividida em duas porções: a primeira delas possui objetivo de sair do caminho de outros robôs e possui maior prioridade que os demais. A segunda porção, de baixa prioridade, tem objetivo de levar o robô até sua posição final.

O algoritmo apresentando na Figura 4 ilustra o processo de cálculo de trajetórias.

\section{Resultados experimentais}

Para validar o método proposto foram executados experimentos utilizando a plataforma de simulação Player/Stage (Gerkey et al., 2003). Nesse ambiente foram propostos mapas com as característi-

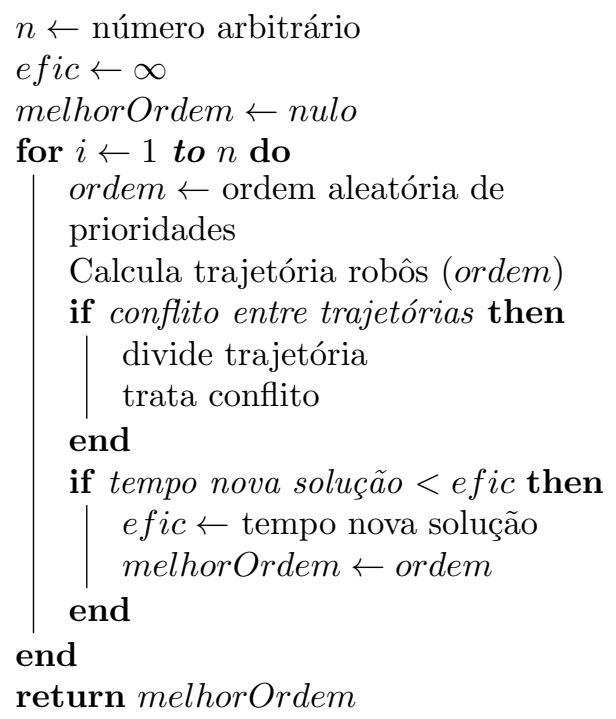

Figura 4: Cálculo de trajetórias

cas apresentadas nas seções anteriores e executadas algumas simulações, variando-se o número de robôs e habilitando gradativamente as heurísticas propostas no decorrer deste trabalho. O intuito do experimento é avaliar a influência da utilização das heurísticas na redução do tempo total para execução da exploração do mapa.

Na Figura 5 é mostrado o tempo médio (em segundos) em que foi realizada a exploração de uma série de mapas (com 45 features cada um deles). São apresentadas três curvas: para a exploração realizada com um robô, dois robôs e três robôs. Para essas curvas foram avaliadas quatro situações distintas:

\section{Alocação de tarefas aleatória;}

2. Heurística da distância do robô à fronteira;

3. Heurística da distância e heurística de fechamento de loop;

4. Heurística da distância, heurística de fechamento de loop e heurística de distribuição dos robôs.

Para a primeira curva, com um robô, pode-se notar uma diminuição significativa do tempo de exploração com a utilização da heurística de menor distância. Optando-se pela fronteira mais próxima ao robô, são evitadas "idas e vindas", fazendo com que a exploração ocorra de uma forma mais setorial e ocasionando uma diminuição da passagem do robô por regiões já exploradas. A adição da heurística de fechamento de loop resulta numa redução menor do tempo exploração. Isso pode ser justificado pelo fato dessa heurística ser aplicada em um menor número de situações, já que não é sempre que existem fronteiras alinhadas podendo, potencialmente, fechar um loop. 


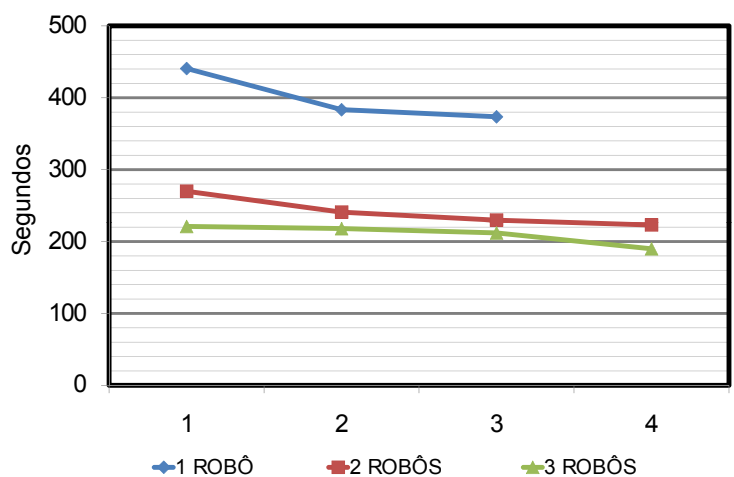

Figura 5: Resultados experimentais

Para a curva de simulação com três robôs um ponto que merece destaque é a aplicação da heurística de distribuição dos robôs, principalmente se comparada com a curva de simulação com dois robôs. A adição dessa heurística resulta em uma maior diminuição do tempo com três robôs o que aponta para uma relação entre a utilização dessa heurística e a densidade de robôs dentro do ambiente estudado. Quando se tem um grande número de robôs em um espaço pequeno é interessante que eles explorem regiões afastadas para evitar a interferência de suas trajetórias e a passagem por regiões já exploradas. Porém, em um ambiente com uma baixa densidade de robôs, é razoável assumir que somente a utilização da heurística de menor distância possa causar uma tendência de afastamento dos robôs, já que inicialmente cada um deles direciona-se para regiões diferentes e, tendo uma baixa densidade, cada robô explora uma região do ambiente, justificando a menor redução de tempo no caso de dois robôs.

\section{Conclusões e perspectivas}

Este trabalho apresenta um método para a exploração de ambientes desconhecidos com sistemas multi-robôs. Esse método abrange desde a fase de mapeamento do ambiente, na qual é realizada a interpretação dos dados sensoriais dos robôs e organização das mesmas na forma de um mapa; até a fase de planejamento de trajetória, em que as tarefas são distribuídas entre os robôs e trajetórias são calculadas.

A exploração de ambientes desconhecidos com sistemas multi-robôs é um problema que possui elevada complexidade teórica. Devido ao fato do ambiente além das fronteiras ser desconhecido, a distribuição de tarefas para os robôs de forma a garantir o menor tempo de exploração possível depende de inúmeros fatores, fazendo com que o grande número de possibilidades leve a uma explosão combinacional. O método proposto apresenta uma forma alternativa de tratar o problema, que apesar de poder apresentar soluções sub-ótimas, apresenta uma solução computacionalmente bas- tante eficiente se comparado a métodos tradicionais centralizados de planejamento.

As perspectivas futuras deste trabalho são a realização de um maior número de experimentos, em ambientes diversificados. Esses experimentos têm como intuito avaliar aspectos como o efeito de cada heurística em ambientes com características específicas (ambientes com mais cruzamentos e com mais becos-sem-saída) e também ampliar os experimentos realizados para um número maior de robôs, com objetivo de comprovar as tendências percebidas.

\section{Referências}

Bando, S. and Yuta, S. (2010). Use of the parallel and perpendicular characteristics of building shape for indoor map making and positioning, Intelligent Robots and Systems (IROS), 2010 IEEE/RSJ International Conference on, IEEE, pp. $4318-4323$.

Burgard, W., Moors, M., Stachniss, C. and Schneider, F. (2005). Coordinated multi-robot exploration, Robotics, IEEE Transactions on 21(3): 376-386.

Carvalho, J. (2012). Modelagem e síntese para coordenação de sistemas multi-robôs baseada numa estrutura de jogo, Dissertação de mestrado, Universidade Federal de Santa Catarina, Departamento de Automação e Sistemas, Florianópolis/SC .

Gerkey, B., Vaughan, R. T. and Howard, A. (2003). The player/stage project: Tools for multi-robot and distributed sensor systems, Proceedings of the 11th international conference on advanced robotics, Vol. 1, pp. 317-323.

Marjovi, A. and Marques, L. (2011). Multi-robot olfactory search in structured environments, Robotics and Autonomous Systems 59(11): 867-881.

Pavei, J. (2011). Coordenação em sistemas multirobôs utilizando métodos baseados em autômatos, Dissertação de mestrado, Universidade Federal de Santa Catarina, Departamento de Automação e Sistemas, Florianópolis/SC.

Stachniss, C., Mozos, O. and Burgard, W. (2006). Speeding-up multi-robot exploration by considering semantic place information, Robotics and Automation, 2006. ICRA 2006. Proceedings 2006 IEEE International Conference on, IEEE, pp. 1692-1697.

Thrun, S. et al. (2002). Robotic mapping: A survey, Exploring artificial intelligence in the new millennium pp. 1-35.

Yamauchi, B. (1997). A frontier-based approach for autonomous exploration, Computational Intelligence in Robotics and Automation, $199 \%$. CIRA'97., Proceedings., 1997 IEEE International Symposium on, IEEE, pp. 146-151. 